\title{
PURLOINED BUD OF SKIN; AN INSIGHT INTO THE FEMALE CIRCUMCISION
}

\section{OF THE BOHRA COMMUNITY IN INDIA}

\author{
RESHMA SARAH EASO ${ }^{1} \&$ VARSHA $\mathrm{K}^{2}$ \\ ${ }^{1}$ M.Phil Scholar, Amrita University Kochi, India \\ ${ }^{2}$ Assistant Professor Amrita School Of Arts And Sciences, Kochi, India
}

\begin{abstract}
Female Genital Mutilation, also called 'Female Cutting' is the horrendous practice of inflicting injury on the female genital. Every year millions of girls are subjected to cutting, hence the United Nations has described it as mutilation. Believed to have its origin in the ancient civilization of Mesopotamia, this practice was a method of controlling women by curbing her sexual desires. It was seen as a method to keep a woman clean and pure. Ancients believed that the genitals of women had the potential to grow long and it would result in penis like structures. Over centuries, this practice has become something like a social norm in many cultures. In India, female circumcision is found in the Bohra Dawoodi community. The Bohras are a well-educated sect with a very good number of literates; it is a surprise that 'Khatna' (circumcision) is still performed in this community. Female circumcision practiced by the Bohras is a very good example, as to how some social norms over time become institutionalized. This paper tries to understand why female circumcision is still practiced in the Bohra community, and it is also an attempt to give readers awareness on the practice.
\end{abstract}

KEYWORDS: Female Genital Mutilation, Tradition, Norm, Institutionalization \& Bohra Community

Received: May 30, 2017; Accepted: Jun 22, 2017; Published: Jul 12, 2017; Paper Id.: IJELAUG20178

\section{INTRODUCTION}

Female Genital Mutilation (FGM), also known as 'Female Circumcision (FC)' and 'Female Cutting' involves all the practices that cause external injuries to the female genital organs in the name of religion, culture and tradition. World Health Organization (WHO) defines Female Genital Mutilation as 'all procedures that involve partial or total removal of the external female genitalia, or other injury to the female genital organs for non-medical reasons'. United Nations General Assembly passed a resolution on 21 December 2012 calling on countries to eradicate FGM. The then secretary general, Ban Ki-moon described the resolution as 'historic' and as a step towards ending violation of human rights against millions of women and girls. According to a survey conducted by the United Nations, around 200 million women in 30 countries have been subjected to the horrendous practice of FGM. Indonesia and the countries of sub- Saharan Africa alone have a whopping number of women and girls, who had to go under the knife. FGM is also practiced in countries like Pakistan, Iran, Iraq, Malaysia, Singapore, Thailand, Bangladesh, Russia, Oman and Yemen. Recently, owing to global migration, FGM has spread to Europe and America as well. In a survey by BBC, it is noted that four woman per hour undergoes FGM. The rationale of female circumcision is based on religion, tradition, cultural facts, myth and an ignorance of biological facts. It is seen as imperative for a woman, so as to reduce her libido, keep up her honor and prevent her from being rebellious. 
I was next. Grandma swung her hand from side to side and said, 'Once this long kintir is removed you and your sister will be pure.' Then the scissors went down between my legs and the man cut off my inner labia and clitoris. I heard it, like a butcher snipping fat off a piece of meat....then came the sewing: the long, blunt needle clumsily pushed into my bleeding outer labia... when the sewing was finished, the man cut the thread off with his teeth (Ali, 2013).

This paper is an attempt to understand the mindset behind Female Genital Cutting among the Dawoodi Bohra community in India, and to give readers awareness on the practice. It is indeed surprising that even in a highly educated community like the Bohras, this procedure keeps on continuing. The risk of female cutting increases with migration. As the community migrates to new countries, the risk of female genital cutting being practiced also increases. It's high time that victims come and speak out against this medieval practice. Awareness on cutting should also increase, making people less shy to speak on it.

The origin of female genital cutting is uncertain, but it is believed that this practice has been in existence before the coming of both Christianity and Islam. Traced back as early to the 2nd century BC, there are written evidences by geographer, Agatharchides of Cnidus who describes circumcision done on both men and women residing on the coast near Red Sea. Therefore, it is widely believed that circumcision originated in Mesopotamia. According to Pharaohnic beliefs, every mortal had bisexual traits like their Gods who were seen as an amalgamation of both genders. Individuals also had a male and female soul and the masculine soul of the woman was at her clitoris while the foreskin of a man held his feminine soul. Both the souls had to be circumcised for the betterment of their own gender. All thorough out, it is believed that the practice of cutting kept a woman's virginity intact as well as reduced her desires. Many African tribes presume that an uncircumcised woman could not enter wedlock. While it is seen as a custom in African countries, in many other regions it is seen as a medical intervention to control masturbation and related nervous disorders. OlayinkaKoso-Thomas notes on the status of African women that,

The eradication of female circumcision must involve the social, religious and cultural transformation of certain communities, rather than overturning or uprooting this base by rapid decrees, because the legislative attempts of the past, which were aimed at prohibiting it, did not succeed (1987).

Some earliest arguments on why Female Genital Cutting was practiced looks onto some worldly terms, rather than explaining it from a religious and ritualistic angle. The most known explanation was that the humid climate of African regions caused the clitoris of the female to grow and this resulted in a penis like structure. To maintain the proper growth of the clitoris cutting was propagated. One other explanation is that, the clitoris produced secretions and megma and cutting the clitoris prevented the smegma from accumulating in the genital area. Some people felt that smegma put off men and displeased them. John Davenpor, an amateur scholar on erotic subjects in his work Circumcision mentions that,

Cleanliness has rendered it necessary. In some climates the nymphae, from their great length, become inconvenient, for in the vicinity of the clitoris of women is collected an acrid and stimulating humor called smegma (from its resemblance to soap), and this secretion is partly covered by the nymphae. This white saponaceous and almost foetid substance is one of the most powerful stimuli of the sexual organ. Thus, such persons as observe great cleanliness are generally less given to venery than those who are negligent in this respect. In cold or even temperate regions this secretion becomes less abundant, and, as it is consequently less active in its effects, the sexual organs are more quiescent than in southern regions (06). 
Female genital cutting is also called as 'female circumcision', 'sexual mutilation' and 'ritual surgery' in academic discourses. At times the term mutilation can add more traumas to a victim and they can be offended by the word. Often, as a compromise and to ensure a more neutral attitude to the victims, the term Female Genital Cutting is used. FGM is categorized as Type1, Type2, Type 3 and Type 4 on the basis of cutting that is done. The description varies according to the removal of the clitoris. $90 \%$ of cases around the world include type1 which is also known as Cliterodectomy. Type1 and Type 2 cuttings do not have much physical complications. Type 3 is at the risk of long term complications like vaginal and urinary infections, infertility, sexual dysfunction, scar formation, tetanus, septicemia, cysts, hepatitis B and HIV are some consequences. Long term complications include chronic and recurrent urinary and pelvic infections that can lead to pooling of menstrual blood in the abdomen. Getting conceived is a great challenge for women who have been cut as the infibulated scar that protects virginity acts as a hindrance for a girl to get pregnant. The scar of female genital mutilation is not merely physical but mental too. Scars are usually formed during infibulations and for these scars to be formed the legs of the victim are tied together after circumcision for around two weeks and during this period urination is done either by standing or leaning. After the healing time the scars are formed over what were once her genitals. This scar is something that she carries life long, reminding her to be chaste and pure. They are marks of her limitations and testimony of the pain she had to go through. During child birth the risk of the woman increases and still birth as well as neonatal birth may occur. Unlike male circumcision that has health benefits there are no proven benefits for female circumcision. Often, people who are not medical practitioners perform the procedures. Unsterilized blades, knives, broken glass, sharp tones, scissors and in some regions sharp and long finger nails and even their teeth are used for cutting; the severity of the process ranges by their geographical location and culture. Based on its various types, female genital cutting has been grouped into four types by WHO (World Health Organisation). Even though the debate on the terms continues among the scholars and researchers, this classification help to understand the term better. (Image credits, Wikipedia)

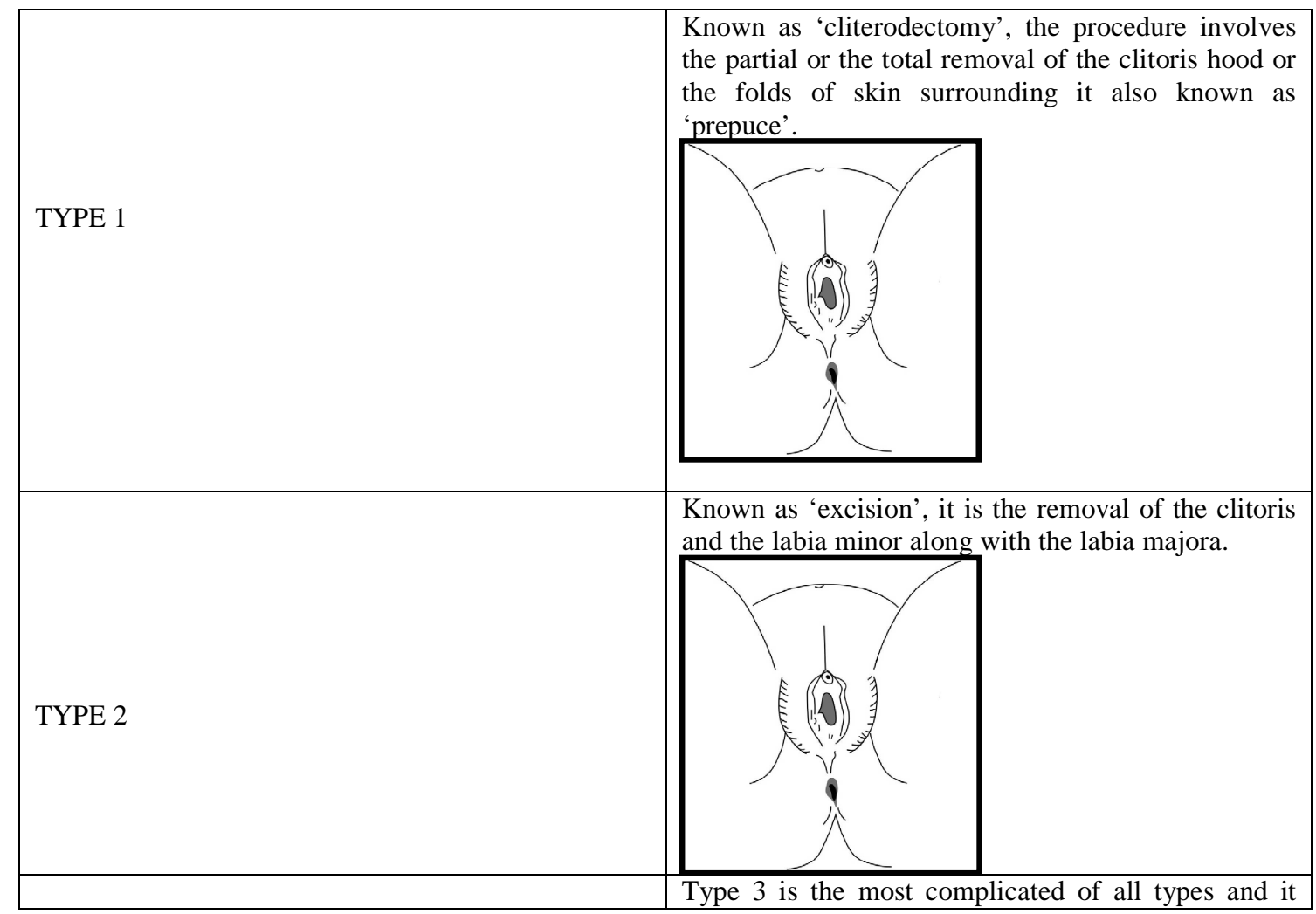




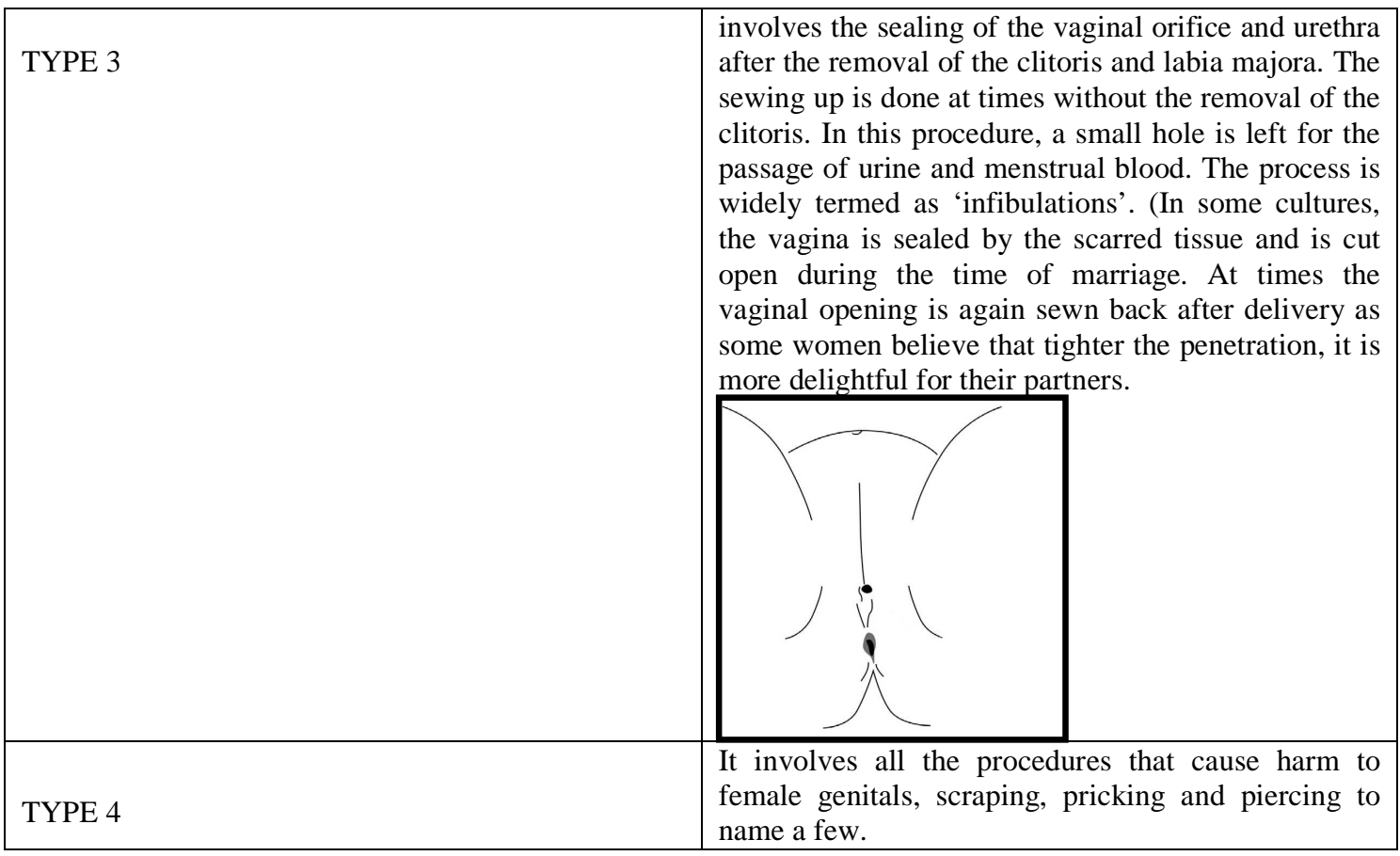

In India, the practice of female mutilation is known to be carried out by a certain community known as the Dawoodi Bohras. With a population between 1 and 2 million, they live all around the world with a big chunk in India and Pakistan. Almost $80 \%$ of women in this community undergo female genital mutilation and even though a lot of people protest against the practice, it still prevails. Dawoodi Bohra community, also known as Western Ismailis, of India traces their ancestry to Fatimid dynasty of Yemen. In about the 10th century they migrated from Yemen and landed on the Western coast of India. Most of them were merchants and they flourished in their trade. Dawoodi Bohras are said to have first settled in Gujarat and hence their main language, Lisam al- Dawat is a unique blend of Gujarathi, Arabic, Urdu and other languages. The community is well-educated and centralized with a hierarchical clergy who is referred as the 'Dawat'. The Bohras are a well knit group and they even have special dresses to mark themselves.

In the Bohra community, circumcision is carried out on boys and girls as a pre-pubescent coming of the age ceremony and the child undergoes it when he/she is around 7 years old. The term 'khatna' or 'khafd' (circumcision) is used to refer to the removal of prepuce from the genitals of boys and girls. During femalekhatna a ceremony is carried out under the guardianship of the elders of the family like grandmother or elderly aunts. Held with a lot of pomp and celebrations, it usually marks a girl's transition to puberty. Female khatna is classified mainly as type 1 female genital mutilation according to the World Health Organisation (WHO). The Bohras believe that the cutting they practice is different from African traditions. But the irony is that all types of circumcision have a shared ideology; to control women. Khatna is performed by a cutter who is also known as a 'mulaani' in a house hold like setting. The role of the cutters is passed on from generation to generation but each cutter should have the approval of the clergy to do the procedure. But nowadays due to concerns of hygiene and as a safe measure, girls are taken to clinics and hospitals for the procedure. The procedure involves pain, bleeding, infection, swelling, difficulty to walk and urinate and at times even tetanus. No benefits of cutting have been proven to date. Natural processes like menstruation, urination and child birth become a difficult process and the traumatic experience that some people have after 'khtana' is severe. Feelings of anger, betrayal and lack of interest in intercourse are 
some after effects.

Tracing the history of the Dawoodi Bohra community, it is seen that most of the early settlers among them were merchants. Even the origin of the term Bohra comes from the Gujarathi word 'Vehru' meaning trade. The men of the family had to travel a lot and be away for long periods of time. In order to make sure that the woman did not have any unwanted desires during her man's absence and to avoid infidelity, the community decided to follow the practice of cutting. There are many explanations as to why this practice is continued in this community. While there are many small factors, the main reason is religious and traditional purposes. Over the years, this practice has made a mark within the community and they have taken it as a norm that they are supposed follow. Female Circumcision is seen as a trademark of their tradition and the elders of every generation do not wish to part themselves from this ritual and so it is carried over from generation to generation. Another reason is to curb sexual arousal and to keep a woman under control. Many parents fear that their daughters might not be marriage materials if they don't undergo the ritual cutting. This fear pushes the elders to force their daughters for 'khatna'. Females who do not undergo cutting are seen as unclean and unhygienic and even labeled as prostitutes. Not just the woman, but an uncircumcised female's whole family is often blamed and secluded. Often in a community gathering, they are looked upon with disgust. There is also a myth that, cutting not only preserves the virginity of a woman but increases her beauty too.

Every society sets up their own norms to have a pattern for its members. A norm is referred as an abstract pattern held in the mind that sets certain limits for behavior. Norms have an intense impact on many decisions that are taken by an individual. Often a social norm is administered by informal social sanctions and these sanctions motivate individuals to follow norms. One typical feature of norms is that they are expected to be followed until the expectations change. Once these normative patterns get recognition from the society they slowly become institutionalized and the society does everything they can to continue this. Institutions often emerge as unplanned entities of a society. People search for patterns for meeting their needs and over time these patterns becomes standardardized due to their repetitions. Slowly with time these patterns acquire power sanctions too. People tend to adapt themselves according to these accepted practices, and over time these patterns redefine themselves to adjust with the changing situations. Some norms are carried on for ages without even knowing why it's been practiced. Norms that were started to regulate social order soon becomes an unavoidable part of the society. Institutional norms are in fact houses of power structures, as Michael Foucault mentions, 'Power is that it transcends politics and sees power as an everyday, socialised and embodied phenomenon.' (Foucault, 26) Foucault also points that being deeply rooted in perceptions; norms cause individuals to discipline themselves and not to fall apart. For him it was not just power with norms but power in bodies that too had a great impact on people. He coined the term 'bio power' to refer to the ways in which, body is seen as the site of subjugation Inside an institutionalized pattern, it is difficult to step aside the pattern or even question it owing to various factors including fear of the society. The same happens in institutionalization, once it enters the comfort zone; one prefers to go on with it, rather than breaking away. Every culture prepares their women as how the man of that culture wishes her to be. Even though this shaping process becomes a restraint for a woman she seldom understands it. For centuries, women in China had their feet broken and toes forced underneath, so that the feet would no more be than 3 inches long. It was often difficult to walk and women had to hobble along. The awful odor of feet rotting became something that men took pleasure in. In fact, the whole process was to prevent a woman from leaving a place. It is with the same ideology of enslavement that many of our routine practices are shaped. Burmese women are supposed to wear a number of heavy necklaces and over time it became difficult for them to hold their necks up. Many things that women think make them beautiful are in fact chains of enslavement that started as 
simple norms and ended up being inseparable. These include the notions of wearing bras, high heeled shoes and even the western concept of a bleached blond woman.

In the case of the Bohra community, the most plausible explanation as to why it's been continued in a community where $80 \%$ of its members are educated, lies in the fact that since the community has its roots in Yemen, they just carried forward the procedure that they practiced there and over time, it became what can best be called as 'social norm'. Even though it began as a procedure to keep a woman's desire down and tackle her, with time the practice became a symbol of the community and it became a must for every female child to undergo khatna. Slowly, a ritual became a norm and a center for institutionalized patterns; this often happens through daily routines which people engage in like health and sex. At times even the female elders did not have a correct explanation as to why a girl has to undergo cutting. It became a typical routine for some families, while for some it is seen as the only link, that thread them with their ancestors and for some others it is a religious practice approved by the 'Dawat'. It is a big surprise that in a country that boasts of women's freedom and rights this is still practiced.

An organisation named 'Sahiyo' has been campaigning against FGC, since 2015. In one of their recent online surveys involving 385 (three hundred eight five) Bohra Dawoodi women, it reveals that around $80 \%$ of them have undergone FGM. The set of reasons that they believe are; religious purposes (56\%), to decrease sexual desire (45\%), to maintain customs (42\%) and to keep good physical hygiene (27\%).

Though female genital mutilation has been practiced through centuries, there is very less protest against the whole procedure. Even a highly educated community having around $80 \%$ of education like the 'Bohras', hesitate to speak against the process; instead they adhere to their norms. Secretive nature of the whole practice and shyness to speak on this topic might be a reason that women do not come forward against it. Many women are nervous to talk about cutting to even their own ones. This inability often terms cutting as a topic of taboo that woman seldom talk about. This forbiddance also results in little restriction against cutting. Even though there are many who prefer silence regarding cutting there have been some who have raised their voices against mutilation. Waris Dire is a Somalian model who in her autobiography, Desert Flower mentions the hardships she had to face during the time of cutting. At one point of the book she writes,

When the ties that bound me were removed from my legs, I was able to look at myself for the first time. I discovered a patch of skin completely smooth except for a scar down the middle like a zipper. And that zipper was definitely closed. My genitals were sealed up like a brick wall that no man would be able to penetrate until my wedding night, when my husband would either cut me open with a knife or force his way in (45).

Such was the terrible experience of cutting. Waris over the years became a well-known model and in one of her interviews she took up the platform to speak on female genital mutilations boldly to the world. She is United Nation's Special Ambassador in the fight against FGM. She has also started a foundation named as Desert Flower in 2002 and the teams are committed to human rights and ending female genital mutilations. The work of Alice Walker, co-authored by Pratibha ParmartitledWarrior Marks deals extensively with female cutting in parts of Africa. In the form of interviews, photos and poems, the book is a piece of work that is extremely open and insightful. Walker writes, 'So. It was a 'tradition.' Their mother had it done to her. Her mother. The elders and ancestors. Yes, of course they would do it to their own girls. I wanted to take them in my arms and fly away with them.' (49) Even though there are a lot of reasons as to why it is difficult to stop female mutilation there are also a lot more reasons as to why we have a better platform than our ancestors to put an end to the practice. Walker describes that; 
It is all about consciousness, and there are now more educated women in the world, more conscious women. In some cultures, men have confused sexuality with torture, so that they only really enjoy sex with a woman, if she is literally screaming in pain....their consciousness is changing, so there will be men, too, who will fight against it, and have been doing so (278).

Who owns the female body is a question that often pops up in several realms. The right to control one's body has become a challenge and that challenge multiples, if you are woman. The 'Second Wave' of feminist movement during the 1970's was the period, when the notion of body politics was first came up. Even though it was initially against the objectification and violence of the female body, soon 'the personal is the political' became a slogan for woman's rights. Till then rape, violence and sexual brutality was stifled in the society and it found a breakage from the same. The body is a ground of battles for a woman, where she is a mere spectator. The social sanctions given to male domination insights the society to look down on female body with contempt. It is the fundamental right of every woman to make decisions and choices regarding her body, for example, reproduction and sexuality that every woman should have the choice for their body, whether to reproduce or for sexual desires. Denial of rights to body highlights woman's subordination in different areas. Throughout history, the female sex has been subjected to cruel customs and barbaric traditional practices that deny them their choices. Female genital mutilation is one such barbaric act, where a female is constrained and subjugated. Many cultures see female sexuality as an impetus that is malicious and needed to be dominated.

Even though writings on Female Genital Mutilation have become common, the inability to protest persists. From the new millennium, many people started to come forward and openly disapprove on this abysmal practice. In India, the constitution guarantees equal right. There are also a number of laws that provide protection to women against any form of harm as well as gender discrimination. Yet, despite the laws and treatises, there has been no action on the part of the State to address the issue and eradicate it. Globally, many NGO's, activists and governments have been trying to curb and curtail the practice. 23 countries in Africa have passed laws banning mutilation over the past decade. United Nations along with WHO is taking up guidelines to stop the practice. February 6th has been commissioned as 'Zero Tolerance Day' in relation with FGM. A slow protest against cutting practiced by Bohra community is gaining pace in India. Petitions are being signed and surveys are being taken place to create awareness and to put an end to the practice. In India, over the decade a few organisations have come forward to join hands against Female Genital Mutilation. The advancement of social networking sites have made it easier to reach out to people. 'Sahiyo' is an NGO founded in 2014 by five women who are strongly against the ritual of Khatna in the Bohra community. The main aim of the organisation is to put an end to the practice by empowering the Bohra community as well as other Asian communities. Sahiyo organizes meetings and forums that provide an opportunity to victims to come out and speak on the practice. The organisation has been an eye opener to many women and has made them aware of their rights. 'Speak Out on FGM' is another advocacy group who are also forerunners against the practice. 'Each One Reach One' was a campaign launched by Speak Out on FGM on February 6th 2016. It was conducted by a group of 50 female genital mutilation survivors and launched a month long campaign on the horrendous practice in Mumbai.

\section{CONCLUSIONS}

As a norm, that has transformed into an institutionalized whole, it's high time the practice is put to an end among the Bohra community, as well as the rest of the world. Educating an empowered generation is the first and foremost step that is to be undertaken to stop the practice. In the case of Bohra community, woman must be encouraged to speak on the 
issue without any hindrance. United Nations has vowed to deplete FGM by 2030 and for this it is necessary that nations and organisations stand together. As mentioned in Infidel by AyaanHirsi Ali, 'You should leave the child as he is, as he comes out of the womb. He's finished. He's complete.'(43) Protests and campaigns are not the only means that would help to eradicating cutting, a mind that would leap beyond norms and break stereotypes is also at the most necessary. Social norms are not easy to give up and education does not always make a difference because not practicing a community's social norms often comes with consequences for the individual. Preventing a tiny cut after all, can make a big difference.

\section{REFERENCE}

1. Ali, AyaanHirsi.(2013). Infidel. New York: Atria Paperback.

2. Davenport, John. (1966). Circumcision in Aphrodisiacs and Love Stimulants, with Othe

3. Chapters on the Secrets of Venus, edited by Alan Hull Watson. New York: Lyle Stuart.

4. Dirie, Waris, and Cathleen Miller.(2013). Desert flower; The Extraordinary Journey of a

5. DesertNomad. London: Virago.

6. Foucault, Michel. (1980). The History of Sexuality. Volume I: An Introduction. Trans by

7. RobertHurley. New York: Vintage.

8. Koso-Thomas,(1987). O. The Circumcision of Women. A Strategy for Eradication. Zed

9. Books,London.

10. Walker, Alice, and Pratibha Parmar.(1996) Warrior Marks: Female Genital Mutilation and

11. TheSexual Blinding of Women. San Diego: Harcourt Brace. 